\title{
Manifestações bucais na infecção pelo Vírus da Imunodeficiência Humana: uma revisão sistemática da literatura.
}

\author{
Oral manifestations in HIV infection: a systematic literature review.
}

Solange Moreira da Silva ${ }^{1}$, Alexandre Lustosa Pereira ${ }^{2}$, Marco Túlio Antônio García-Zapata ${ }^{3}$

\begin{abstract}
The purpose of this study was to develop a systematic literature review using DECs descriptors (BVS) and Mesh Terms (PubMed) in specific data bases (PubMed, Scopus, ScieLO, Lilacs and CAPES) to verify the prevalence and the meaning for the oral manifestations in HIV infection. It was accepted articles in English, Portuguese and Spanish since 2000 until 2012. 337 articles were identified, but only $20(5,93 \%)$ were included after Relevance Tests I and II. It was possible to conclude that prevalence for oral manifestations in HIV patients ranged from $19,5 \%$ to $85 \%$ at different regions around the world. The most prevalent lesion was oral candidiasis followed by oral hairy leukoplakia. Neoplasms are not so frequent anymore. Oral candidiasis has been considered a marker for immunedepression and AIDS and for therapeutic failure. These lesions may be useful on monitoring the disease progression at developing countries.
\end{abstract}

Keywords: Mouth diseases. Oral manifestations. Aids-related opportunistic infections.

\section{Resumo}

O propósito deste estudo foi o de realizar uma Revisão Sistemática da Literatura por meio de descritores DECs (BVS) e Mesh Terms (PubMed) em bases de dados específicas (Scielo, Scopus, Lilacs, PubMed e CAPES) para investigar a prevalência e o significado das manifestações bucais na infecção pelo HIV na visão de diferentes autores. Foram identificados 337 artigos científicos que utilizaram padrões de avaliação similares em indivíduos infectados pelo HIV a partir de 18 anos de idade. Após a aplicação dos Testes de Relevância I e II resultaram 20 artigos científicos (5,93\%). Foram excluídos artigos de revisão, relatos de caso, atualizações e anais de congressos. Concluiu-se que: a) a prevalência destas lesões variou entre $19.5, \%$ a $85 \%$ em diferentes regiões do mundo; b) As lesões mais frequentes foram de origem fúngica, principalmente a candidose em suas diferentes formas. Em segundo lugar esteve a Leucoplasia Pilosa Bucal, lesão de origem viral; c) neoplasias da cavidade oral apresentaram baixas prevalências; d) podem ser os primeiros sinais da infecção pelo HIV; e) a Candidose Bucal está associada à depleção de linfócitos TCD4 e ao aumento da carga viral e pode ser considerado um marcador para imunodepressão e AIDS e para a falha terapêutica em pacientes HIV+ sob o uso de Antirretrovirais; f) são úteis para monitorar a progressão da doença em países com poucos recursos financeiros.

Palavras-chave: Manifestações bucais. Doenças da boca. Infecções oportunistas relacionadas à AIDS.

\author{
${ }^{1}$ Mestranda em Ciências da Saúde pela Universidade Federal de Goiás (UFG) - \\ Goiânia \\ ${ }^{2}$ Doutorando em Periodontia na Universidade de Taubaté (UNITAU) \\ ${ }^{3}$ Professor Titular do Instituto de Patologia Tropical e Saúde Pública (IPTSP) da
} Universidade Federal de Goiás (UFG)-Goiânia

Correspondência: Solange Moreira da Silva

Endereço: Avenida T 01, 962, apto. 1602, Edifício Solar Bueno, Setor Bueno - CEP 74210-045

Fone: (62) 84246648

E-mail: solmor@cultura.com.br

Data de Submissão: 11/07/2011

Data de Aceite: 08/05/2012

\section{Introdução}

A imunodepressão está presente em pacientes com o vírus HIV-1 onde há grande susceptibilidade às infecções por germes oportunistas e ao aparecimento de neoplasias (REZENDE, 2011). As manifestações da infecção pelo HIV têm caráter oportunista e podem afetar cabeça, pescoço e cavidade bucal, incluindo as adenopatias reativas difusas (GILEVA et al., 2004). O Sarcoma de Kaposi (KS), câncer patognomônico da AIDS, causado pelo herpes vírus associado ao sarcoma de Kaposi (KSHV) está em declínio com o advento da Terapia Antirretroviral. Linfomas podem surgir por ação do vírus Epstein- Barr (EBV) (KALLINGS, 2008; LAGER et al., 2003; NARANI; EPSTEIN, 2001).

Em 1992, uma classificação das lesões bucais associadas ao HIV foi estabelecida no European Community Clearinghouse on Oral Problems related to HIV infection, London (ECC). Revisada em 1993, é bastante utilizada, sendo recomendada e adaptada pela Organização Mundial de Saúde (OMS) para emprego em estudos epidemiológicos. Nesta classificação as lesões foram agrupadas em: Lesões fortemente associadas à infecção pelo HIV (Grupo l): candidoses; leucoplasia pilosa bucal (LPB); sarcoma de Kaposi (KS); linfoma não-Hodgkin (LNH) e doença periodontal na forma de Eritema Linear Gengival (ELG), Gengivite Ulcerativa Necrotizante (GUN) e Periodontite Ulcerativa Necrotizante (NUP); lesões menos associadas à infecção pelo HIV (Grupo II): infecções bacterianas (Mycobacterium avium intracellulare) hiperpigmentação melanótica; estomatite ulcerativa necrotizante; doença de glândula salivar; púrpura trombocitopência; úlceras inespecíficas (NOS); infecções virais; lesões vistas na infecção pelo HIV (Grupo III): infecções bacterianas (Actinomyces israelii); úlceras reativas a drogas e eritema multiforme; infecção fúngica diferente de candidíase (Cryptococcus neoformans; Histoplasma capsulatum; Aspergillus flavus); distúrbios neurológicos (neuralgia do trigêmeo); estomatite aftosa recorrente; infecção viral (Citomegalovírus e Molluscum contagiosum).

A literatura demonstra uma diversidade de manifestações em diferentes regiões do planeta, influenciadas por fatores étnicos, sociais, geográficos, demográficos e imunológicos (PATTON, 2000; CHATTOPADHYAY et al., 2005). Diante deste quadro foi desenvolvida uma Revisão Sistemática da Literatura, utilizando a 
estratégia de Muñoz ( 2002) buscando estudos originais semelhantes com o objetivo de averiguar a frequência e o significado destas manifestações em indivíduos adultos infectados pelo HIV nos últimos dez anos.

\section{Método}

Um protocolo foi previamente delineado para esta revisão e pode ser acessado diretamente com o autor. A seguir, foi realizado um levantamento bibliográfico de artigos científicos indexados nas seguintes bases de dados: Pub Med, Scopus, Scielo, Lilacs e Capes nos dias 06 e 07 de janeiro de 2012. A busca manual foi realizada nas listas de referências dos artigos incluídos, com o objetivo de acrescentar algum estudo relevante não identificado. Os descritores DECs (BVS) e Mesh Terms (Pub Med) foram utilizados nesta busca e todas as possibilidades de agrupamentos destes foram testadas. As associações que produziram melhores resultados foram: manifestações bucais e infecções oportunistas relacionadas com a AIDS, mouth diseases and AIDS- related opportunistic infections e correspondentes em espanhol. O número de artigos encontrados nas diferentes bases de dados é mostrado na Tabela 1. A busca foi realizada por dois pesquisadores na mesma data e horário. Os critérios de inclusão dos artigos foram: estudos com critérios padronizados de diagnóstico clínico (ECC/WHO Criteria) ou similares, estudos em adultos a partir de 18 anos, em inglês, espanhol ou português, sem restrições quanto a países. O período de busca foi do ano 2000 até a data do levantamento de dados. Na base de dados PubMed, foram utilizados a combinação dos Mesh Terms "mouth diseases" and "AIDS-related opportunistic infections" incluindo estudos que abordassem classificação, complicações, diagnóstico, epidemiologia, etiologia e patologia. Foram empregados limites para os últimos dez anos, em humanos, que tratassem de AIDS e nos idiomas pré-determinados. Foram excluídos estudos em crianças, em idiomas diferentes e estudos que não empregaram critérios padronizados de diagnóstico. Foram descartadas revisões da literatura, atualizações, cartas, editoriais, relatos de caso, workshops e anais de congressos. Os artigos identificados foram submetidos ao Teste de Relevância I, aplicado aos seus respectivos resumos. Aqueles resultantes foram avaliados no Teste de Relevância II, aplicado aos textos na íntegra (DELLEON SILVA et al., 2010). Os artigos resultantes foram avaliados e discordâncias foram solucionadas por consenso. Quando necessário, um terceiro revisor foi consultado.

\section{Resultados}

Inicialmente foram identificados 337 artigos científicos e após os Testes de Relevância I e II, foram selecionados 34. Os artigos excluídos não se adequaram aos critérios de inclusão ou eram repetidos. Após o Teste de Relevância II foram excluídos, consensualmente, 14 estudos, por incluírem menores de 18 anos e um artigo, por ser de atualização. Finalmente, 20 artigos foram selecionados. Não foram encontrados artigos na Biblioteca Cochrane (Tabela 1). Os artigos incluídos foram analisados de forma independente por dois pesquisadores segundo o Índice de Concordância (IC), que neste estudo foi de $90 \%$. Foram coletados dados quanto à autoria, período do estudo, amostra, método, prevalência e significado das manifestações em indivíduos HIV IAIDS (Tabela 2).
Tabela 1 - Número de artigos identificados nas bases de dados

\begin{tabular}{llll}
\hline Base de dados Data $\quad N^{\circ}$. Estudos TR I TR II &
\end{tabular}

\begin{tabular}{lcccc}
\hline PubMed & $06 / 01 / 2012$ & 138 & 42 & 21 \\
Capes & $07 / 01 / 2012$ & 1 & 0 & 0 \\
Lilacs & $06 / 01 / 2012$ & 42 & 1 & 1 \\
Scielo & $06 / 01 / 2012$ & 1 & 0 & 0 \\
Scopus & $07 / 01 / 2012$ & 149 & 14 & 7 \\
$\begin{array}{l}\text { Busca } \\
\text { manual }\end{array}$ & $07 / 01 / 2012$ & 6 & 5 & 5 \\
Total & & 337 & 62 & 34 \\
\hline
\end{tabular}

\section{Discussão}

Algumas lesões bucais são características da infecção pelo HIV. A candidose bucal (CB), lesão fúngica, se confirmou como a mais comum em pacientes HIVIAIDS. A prevalência variou de 1,5\% na fase inicial da infecção pelo HIV (MATEE; SCHEUTZ; MOSHY, 2000 ) até $70 \%$ em estudo ugandense (PATTON, 2000; CHATTOPADHYAY et al., 2005; MEDEIROS et al., 2007; TIRWOMWE et al., 2007). Pacientes sob HAART apresentaram uma redução de 20,3\% para 16,7\% (PATTON et al., 2000), o que foi consistente com o estudo de Greenwood, Zakrzewska e Robinson (2002) que observou uma leve redução na frequência de candidose pseudomembranosa de $6,4 \%$ para $5,1 \%$. Por outro lado, a prevalência elevou-se $(66 \%)$ na Alemanha (SCHMIDT WESTHAUSEN et al., 2000) e em Uganda (70\%) (TIRWOMWE et al., 2007). As formas se revezaram entre pseudomembranosa, eritematosa e queilite angular, podendo ocorrer simultaneamente. As duas primeiras se alternaram como as formas mais frequentes (KHONGKUNTHIAN et al., 2001; RAMIREZ-AMADOR et al., 2003; ADUROGBANGBA et al., 2004). A presença desta lesão sugeriu associação ao gênero feminino, à redução do número de linfócitos TCD4 e ao aumento da carga viral e CP mostrou-se associada ao estágio clínico infecção pelo HIV (CAMPISI et al., 2001). Associada ao vírus Epstein-Barr (EBV), a leucoplasia pilosa bucal afeta a borda lateral da língua de indivíduos HIVIAIDS ou de imunocomprometidos em geral (FREZZINI et al., 2006). É a segunda lesão mais frequente nestes pacientes, podendo ocorrer simultaneamente à candidose (PATTON, 2000) e sugerem falha terapêutica em pacientes com ART (CHERRY-PEPPERS et al., 2003). Pouco frequente ou mesmo ausente em diferentes regiões (ADUROGBANGBA et al., 2004; AGWU et al., 2008; TIRWOMWE et al., 2007; CHIDZONGA et al., 2008) mas com alta prevalência na Alemanha e Tailândia (SCHMIDTWESTHAUSEN et al., 2000; KERDPON et al., 2004). O emprego de antifúngicos, gênero masculino, comportamento bissexual e melhor nível educacional facilitaram o surgimento desta lesão (CHATTOPADHYAY et al., 2005), mas ART promoveu redução (GREENWOOD; ZAKRZEWSKA; ROBINSON, 2002). No Brasil, a prevalência se manteve similar à de outros países, variando de $9,3 \%$ a 21,05\% (PINHEIRO et al., 2004; MEDEIROS et al., 2007). 


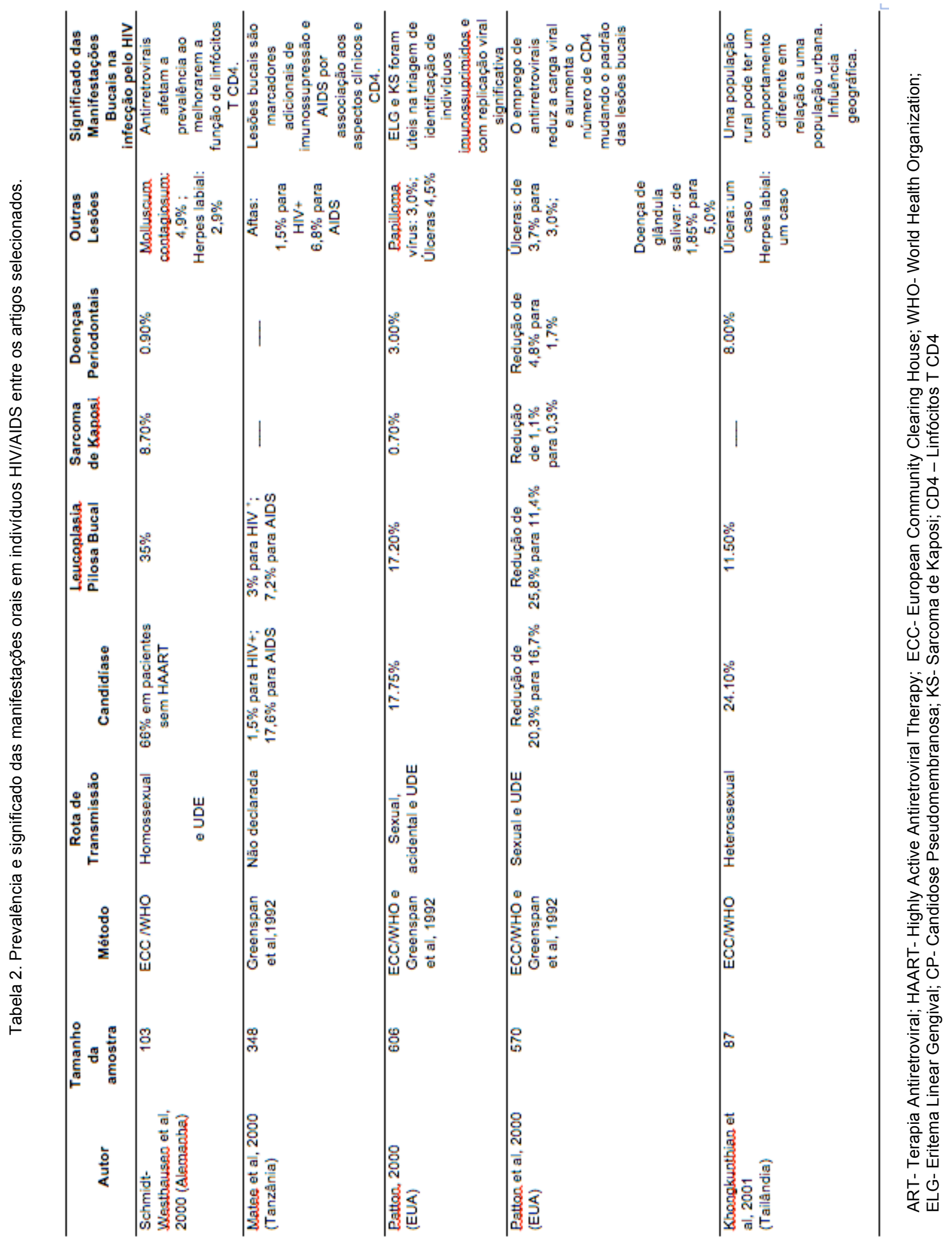

Rev. Fac. Odontol. Porto Alegre, v. 52, n. 1/3, p. 57-65, jan./dez., 2011. 


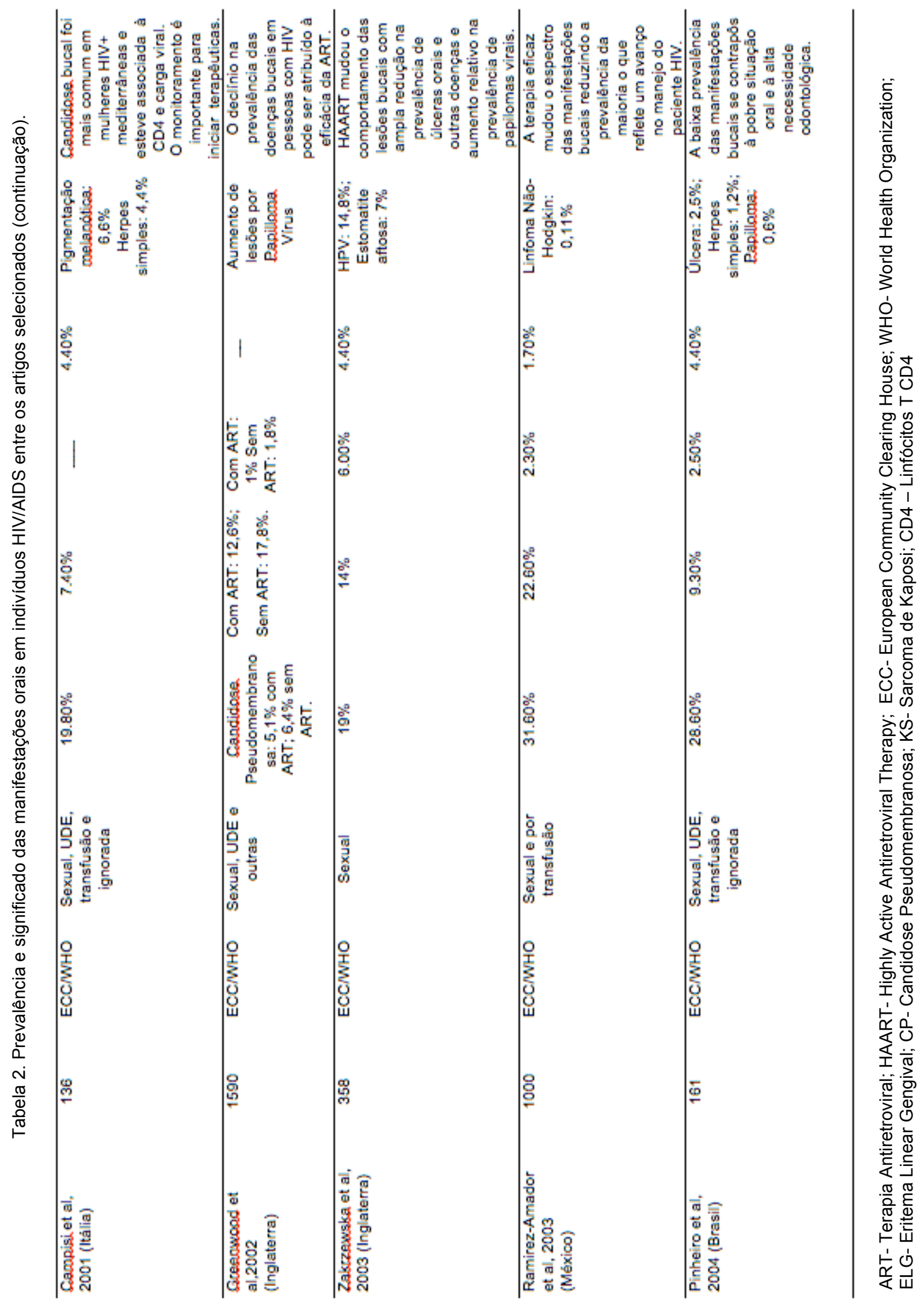

Rev. Fac. Odontol. Porto Alegre, v. 52, n. 1/3, p. 57-65, jan./dez., 2011. 


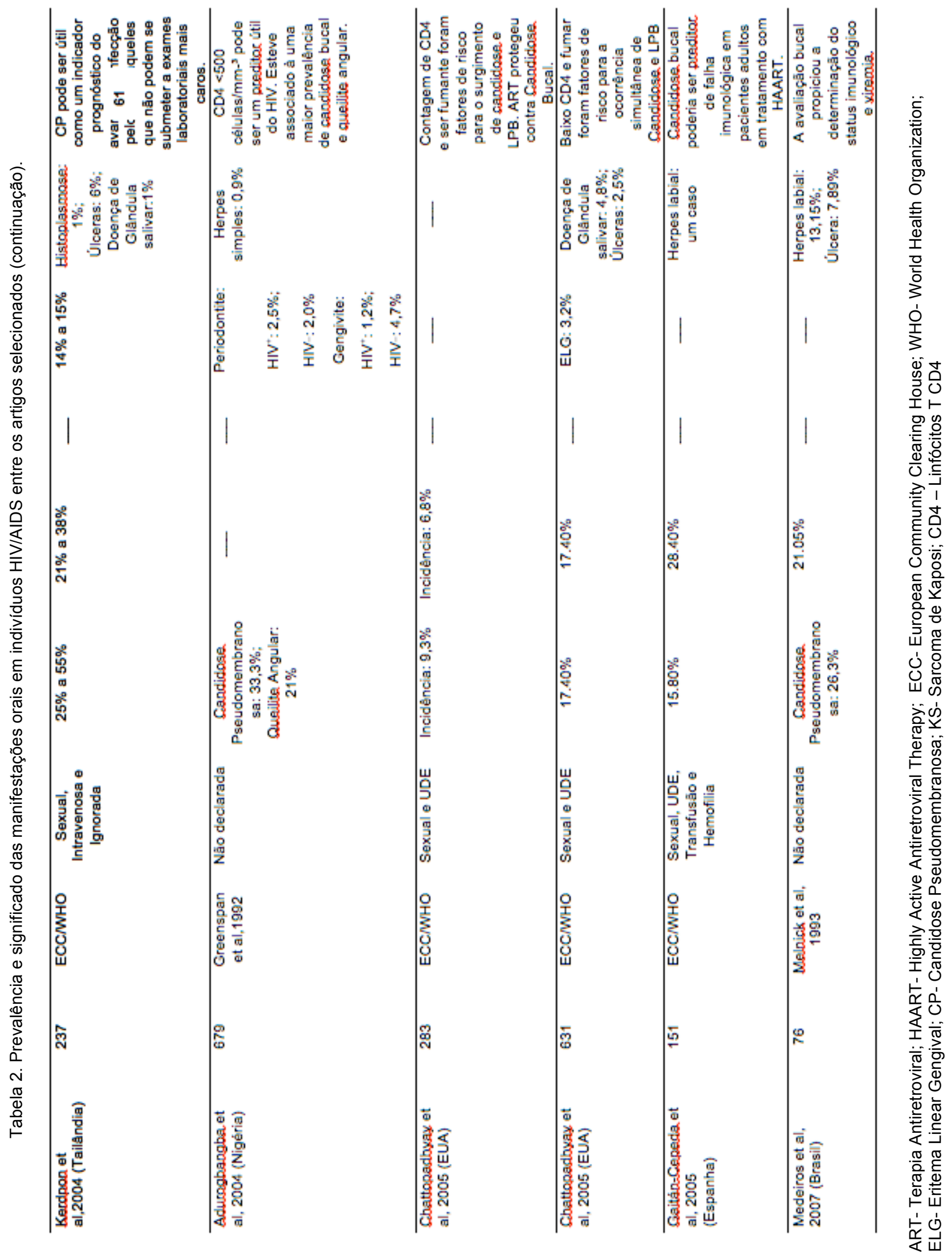

Rev. Fac. Odontol. Porto Alegre, v. 52, n. 1/3, p. 57-65, jan./dez., 2011. 


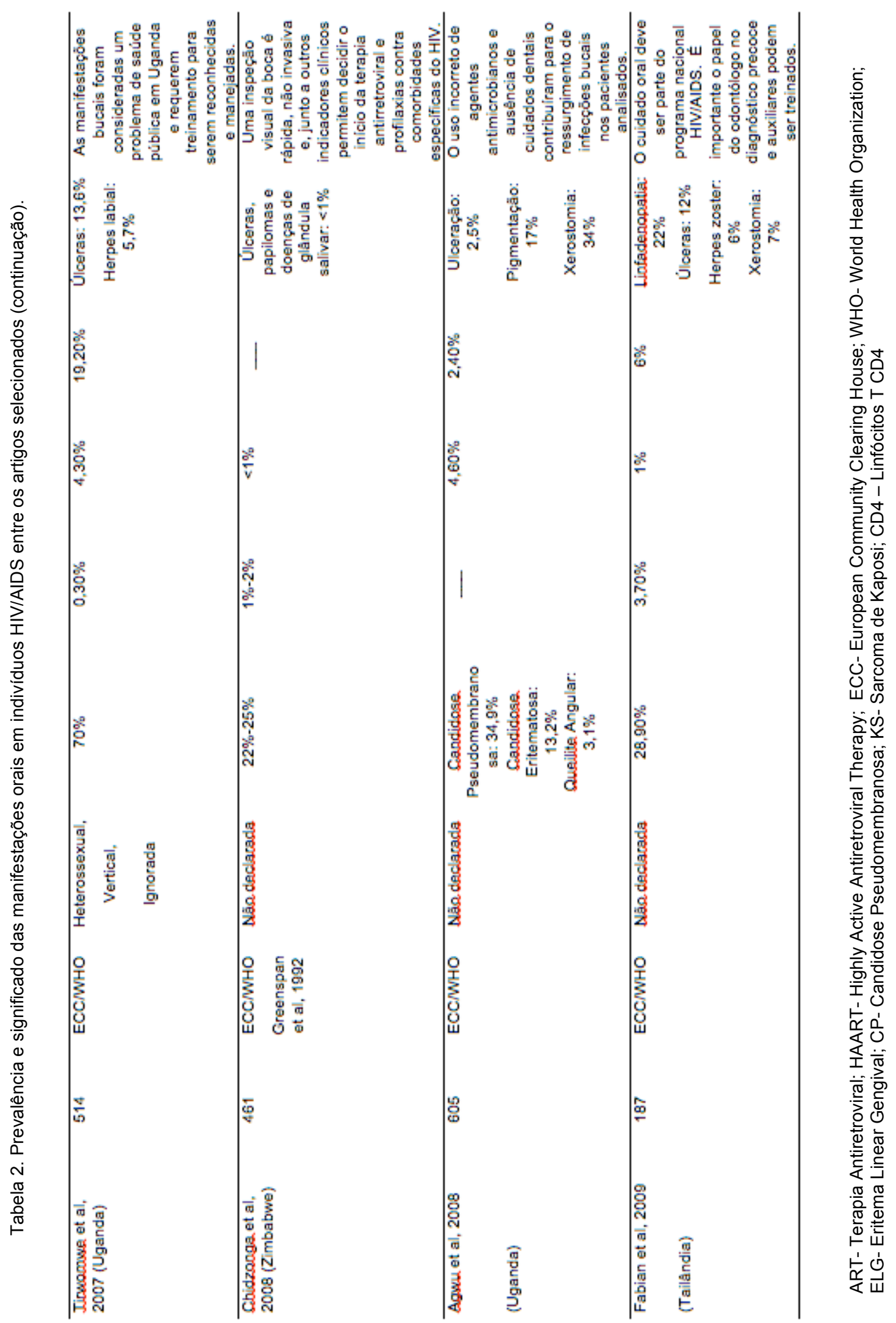

Rev. Fac. Odontol. Porto Alegre, v. 52, n. 1/3, p. 57-65, jan./dez., 2011. 
Duas lesões malignas são comuns no paciente HIVIAIDS: o Sarcoma de Kaposi (KS) causado pelo Herpes Vírus Humano tipo 8 (HHV-8) e o Linfoma não Hodgkin (LNH). KS, associado a uma contagem de CD4<200 células $/ \mathrm{mm}^{3}$, se manifestam como máculas, pápulas ou nódulos que ulceram e destroem o local afetado. Em $70 \%$ dos casos ocorre concomitantemente na pele e vísceras (FREZZINI et al., 2006). Schmidt-Westhausen et al., 2000 detectou uma prevalência de $8,7 \%$. Baixas prevalências ou ausência desta manifestação foram comuns em vários estudos (PATTON et al., 2000; CHIDZONGA et al., 2008; RAMIREZ-AMADOR et al., 2007; TIRWOMWE et al., 2007; ADUROGBANGBA et al., 2004, PINHEIRO et al., 2004; MEDEIROS et al., 2007).

Doença gengival e periodontal relacionada ao HIV têm origem bacteriana e são comuns em pacientes $\mathrm{HIV}^{+}$, principalmente nos países em desenvolvimento. O Eritema Linear Gengival (ELG) forma um halo eritematoso frequente na gengiva marginal de dentes anteriores. Gengivite Ulcerativa Necrotizante (NUG) e Periodontite Ulcerativa Necrotizante (NUP) são processos infecciosos com áreas de necrose superficiais (NUG) ou que afetam os tecidos de suporte, causando dor, odor fétido e desconforto (NUP) (FREZZINI et al., 2006). Foram pouco frequentes (SCHMIDT-WESTHAUSEN et al., 2000; PATTON, 2000; RAMIREZ-AMADOR et al., 2003; FABIAN et al., 2009) ou ausentes nos estudos revisados (MATEE; SCHEUTZ; MOSHY, 2000; GREENWOOD; ZAKRZEWSKA; ROBINSON, 2002; MEDEIROS et al., 2007)), tendo sugerido relação com o emprego de inibidores da protease (PATTON et al., 2000), mas não a um número de Linfócitos CD4 < 200 células $/ \mathrm{mm}^{3}$ (KERDPON et al., 2004). No Brasil, a prevalência tem se mostrado baixa (PINHEIRO et al., 2004; MEDEIROS et al., 2007), mas em Uganda foi de quase $20 \%$, talvez pelo difícil acesso à atenção odontológica (TIRWOMWE et al., 2007). O Edema de glândulas salivares inclui condições inflamatórias reativas, infecções e neoplasias. Na parótida pode estar associado à linfadenopatia generalizada e a um possível envolvimento de polyoma vírus (FREZZINI et al., 2006). Causa xerostomia, o que implica em danos importantes à estrutura dental (CHERRY-PEPPERS et al., 2003). Foi pouco frequente em adultos, embora aumentassem em indivíduos tratados com inibidores da protease (PATTON, 2000; PATTON et al., 2000; ADUROGBANGBA et al., 2004). No estudo de Chattopadhyay et al, 2005, uma prevalência de $4,8 \%$ foi verificada, contrapondo-se a uma frequência de menos de 1\% em 2008 (CHIDZONGA et al., 2008).

Lesões do herpesvírus humano simplex - 1(HSV-1), comuns nestes pacientes, devem ser tratadas para evitar disseminação (CHERRY-PEPPERS et al., 2003). A prevalência variou de $0,9 \%$ (ADUROGBANGBA et al., 2004) a $1 \%$ (KHONGKUNTHIAN et al., 2001) e no Brasil, Medeiros et al, 2007 aferiu uma frequência importante, de $13,15 \%$. Lesões pelo Vírus Herpes Zoster atingem qualquer trecho do nervo trigêmeo dentro da cavidade oral (ulcerações) ou externamente (crostas) (CHERRYPEPPERS et al., 2003). Apenas Fabian et al, 2009 averiguou uma prevalência de $6 \%$.

Lesões bucais causadas pelo HPV surgem como papiloma, hiperplasia epitelial ou condiloma acuminado (SANJAR; QUEIROZ; MIZIARA, 2011). A introdução de inibidores da protease tem sugerido um aumento no número de casos (PATTON et al., 2000), o que foi confirmado por Greenwood et al. (2002) e Zakrzewska et al. (2003). Possivelmente porque a reconstituição de células T pelo ART resulte em células menos imunocompetentes (SCMHMIDTWESTHAUSEN et al., 2000).

Úlceras aftosas acometem lábios, mucosa bucal, língua, orofaringe e vestíbulos (CHERRY-PEPPERS et al., 2003). Cerca de $60 \%$ dos artigos desta RSL a apontam ainda que com baixas prevalências (KHONGKUNTHIAN et al., 2001; PINHEIRO et al., 2004; CHATTOPADHYAY et al., 2005) o que permite supor que são comuns nesta população. A prevalência de $1,5 \%$ em pessoas HIV e de $6,8 \%$ em pacientes com AIDS enfatiza a importância do estágio da infecção pelo HIV no surgimento destas lesões (MATEE; SCHEUTZ; ROBINSON, 2000). Houve redução quando do emprego de HAART (ZAKRZEWSKA; ATKIN, 2003) como visto no Brasil por Pinheiro et al, $2004(2,5 \%)$. Medeiros et al. (2007) constatou um frequência de $7,89 \%$, fato que poderia sugerir um aumento dos casos mesmo com o uso de HAART . Corroborando com o estudo anterior, Fabian et al. (2009), identificou 12\% na frequência destas lesões na Tanzânia.

Lesões de Molluscum contagiosum, têm etiologia viral (Poxvirus) e produzem efeito estético danoso ao afetarem a face (TZUNG et al., 2004). Apenas Schmidt-Westhausen et al, 2000 verificou uma prevalência de $4,9 \%$ na Alemanha caracterizando-a como um desfecho raro.

Algumas doenças oportunistas são raras, como o líquen plano erosivo e úlceras tuberculosas (KAMIRU; NAIDOO, 2002) assim como máculas, pápulas e úlceras bucais causadas pelo fungo Penicillium marneffei (KHONGKUNTHIAN et al., 2001). Viagens internacionais facilitam a emergência de doenças restritas a regiões geográficas específicas em outras absolutamente improváveis. É o caso da histoplasmose, causada pelo fungo Histoplasma capsulatum (FERREIRA; BORGES, 2009) que resulta em úlcera necrótica bucal. $O$ fenômeno tem sido observado no nordeste irlandês em pacientes que contraíram esta micose na África Subsaariana e E.UA (CAREY et al., 2002). Apenas Kerdpon et al. (2004) verificou 1\% na prevalência desta doença. As parasitoses, não demonstraram implicação etiológica em lesões bucais relacionadas ao HIVIAIDS na África do Sul apesar da população estudada estar em uma área pobre e com hábitos de higiene precários (AGWU et al., 2009).

$\mathrm{O}$ advento da HAART refletiu em diminuição no surgimento de infecções oportunistas e prolongamento da sobrevida dos pacientes HIVIAIDS, mas os efeitos positivos não protegeram suficientemente contra lesões induzidas pelo HPV e KS (SCHMIDT-WESTHAUSEN et al., 2000; PATTON et al., 2000; KHONGKUNTHIAN et al., 2001; GREENWOOD; ZAKRZEWSKA; ROBINSON, 2002; RAMÍREZAMADOR et al., 2003). O aumento de papilomas bucais é relevante por se tratar de uma lesão desfigurante, recorrente e com forte impacto psicológico. Requerem acompanhamento devido à possibilidade de malignização (GREENWOOD; ZAKRZEWSKA; ROBINSON, 2002). ART sugeriu ter uma função protetora para o evento simultâneo de CB e LPB (CHATTOPADHYAY et al., 2007).

As manifestações bucais nos pacientes HIVIAIDS podem ser os primeiros sinais da doença e na África, representam um sério problema de saúde pública (MATEE; SCHEUTZ; MOSHY, 2000; TIRWOMWE et al., 2007; FABIAN et al., 2009). Combinado a outros marcadores clínicos, podem auxiliar na tomada de decisão para iniciar ART ou regimes profiláticos para comorbidades específicas da infecção pelo HIV (CHIDZONGA et al., 2008). A presença dessas lesões outorga ao cirurgião-dentista a responsabilidade de reconhecer precocemente os sinais de imunossupressão dos pacientes (MEDEIROS et al., 2007; FABIAN et al., 2009).

Lesões bucais fortemente associadas à contagem de CD4 e carga viral, foram consideradas marcadores clínicos da viremia pelo HIV e da destruição do sistema imune com a progressão da doença (PATTON, 2000; CAMPISI et al., 2001; KERDPON et al., 2004; CHIDZONGA et al., 2008). CP pode ser um indicador na evolução da infecção pelo HIV, sobretudo para aqueles que não têm acesso a exames laboratoriais (KERDPON et al., 2004; ADUROGBANGA et al., 2004). Em pacientes sob HAART, CB foi considerado um preditor de falha imunológica em adultos HIVIAIDS, o que não se aplicou à LPB (GAITÁN-CEPEDA; MARTINEZ-GONZALEZ; CEBALLOSSALOBRENA, 2005).

Os estudos incluídos nesta revisão apresentaram limitações, como amostra predominantemente feminina presente em $30 \%$ do total de artigos selecionados (PATTON, 2000;KHONGKUNTHIAN et al., 2001) ou masculina em 35\% dos artigos (GREENWOOD et al., 
2002; ZAKRZEWSKA;ATKIN, 2003; RAMIREZ-AMADOR et al., 2003). A contagem de linfócitos TCD4 esteve indisponível em 15\% dos artigos incluídos (PINHEIRO et al., 2004;GREENWOOD; ZAKRZEWSKA;ROBINSON., 2002). Vieses são evidentes em estudos apenas em negros (PATTON et al., 2000; TIRWOMWE;RWENYONYI;MUWAZI,2007), grávidas ( ADUROGBANGBA et al., 2004) ou sem pareamento no grupo controle (MATEE; SCHEUTZ;MOSHY, 2000). Amostras de conveniência foi outro ponto negativo observado (KHONGKUNTHIAN et al., 2001;PINHEIRO et al.; ZAKRZEWSKA; ROBINSON, 2004; FABIAN et al., 2009). Contudo, alguns artigos mostraram um alto rigor metodológico como randomização, critérios de inclusão claros e emprego de análise estatística rigorosa (AGWU et al., 2008; CHATTOPADHYAY et al., 2005; PATTON, 2000; KERDPON et al., 2004).

Apesar das limitações observadas foi possível concluir que as manifestações bucais na infecção pelo HIV apresentaram uma prevalência variável $(19,5 \%$ a $85 \%)$. As mais comuns foram as candidoses, seguidas da LPB. Podem estar no início da infecção pelo HIV e Candidose Bucal pode estar associada à depleção de linfócitos TCD4 e ao aumento da viremia sendo considerado um marcador da imunodepressão pelo HIV e para uma eventual falha terapêutica nos pacientes sob ART. Drogas eficazes reduziram a prevalência destas lesões, apesar de emergirem doenças pouco vistas, como a doença de glândulas salivares. O melhor conhecimento da doença AIDS, o acesso a ART e a melhoria no diagnóstico e manejo das lesões bucais influenciam na diminuição da prevalência total destas lesões em pacientes HIVIAIDS (RAMIREZ-AMADOR et al., 2003).

Os autores não têm conflitos de interesse a declarar.

\section{Referências}

ADUROGBANGBA, M.I. et al. Oro-facial lesions and CD4 counts associated with HIVIAIDS in an adult population in Ohio State, Nigeria. Oral Dis., Copenhagen, v. 10, no. 6, p. 319-326, Nov. 2004.

AGWU, E. et al. Appraisal of oral lesions status of HIVIAIDS patients in South Western Uganda. Braz. J. Oral Sci., Piracicaba, v. 7, no. 26, p. 1591-1595, July/Sept. 2008.

CAMPISI, G. et al. Gender differences in human immunodeficiency virus-related oral lesions: an Italian study. Oral Surg. Oral Med. Oral Pathol. Oral Radiol. Endod., St. Louis, v. 91, no. 5, p. 546-551, 2001.

CAREY, F.M. et al. Histoplasmosis as a presentation of Human Immunodeficiency Virus Infection. Ulster Med. J., Belfast, v. 71, no. 2, p. 147-149, Nov. 2002.

CHATTOPADHYAY, A. et al. Incidence of oral candidiasis and oral hairy leukoplakia in HIV- infected adults in North Carolina. Oral Med.

Oral Surg. Oral Pathol. Oral Radiol. Endod., St. Louis, v. 99, no. 1, p. 39-47, Jan. 2005

CHATTOPADHYAY, A.; PATTON, L.L. Risk Indicators for HIVassociated jointly occurring oral candidiasis and oral hairy leukoplakia. AIDS Patient Care STDS, Larchmont, v. 21, no. 11, p. 825-832, Nov. 2005.

CHERRY-PEPPERS, G. et al. Oral manifestations in the era of HAART. J. Natl. Med. Assoc., Washington, v. 95, Suppl. 2, p. 21S32S, Feb. 2003
CHIDZONGA, M.M. et al. Oral candidiasis as a marker of HIV disease progression among Zimbabwe women. J. Acquir. Immune Defic. Syndr., Hagerstown, v. 47, no. 5 p. 579-584, Apr. 2008.

CLASSIFICATION and diagnostic criteria for oral lesions in HIV infection. EC-Clearinghouse on Oral Problems Related to HIV infection and WHO Collaborating Centre on Oral Manifestations of the Immunodeficiency Virus. J. Oral Pathol. Med., v. 22, no. 7, p. 289291, Aug. 1993.

DELLEON SILVA, H. et al. Avaliação de métodos de concentração e detecção molecular de adenovírus em águas não tratadas - uma metanálise. Rev. Soc. Venez. Microbiol., Caracas, v. 30, no. 1, p. 65-71, jun. 2010.

FABIAN, F.M et al. Oral manifestations among people living with HIVIAIDS in Tanzania. Int. Dent. J., London, v. 59, no. 4, p. 187-191, Aug. 2009.

FERREIRA, M.S.; BORGES, A.S. Histoplasmose. Rev. Soc. Bras. Med. Trop., Uberlândia, v. 42, n. 2, p. 192-198, Mar./Apr. 2009.

FREZZINI, $C$ et al. Aspects of HIV disease relevant to dentistry in the 21 st century. Dent. Update, Guildford, v. 33, no. 5, p. 276-286, June 2006.

GAITÁN-CEPEDA, L.A.; MARTINÉZ-GONZÁLEZ, M.; CEBALLOSSALOBREÑA, A. Oral candidosis as a clinical marker of immune failure in patients with HIVIAIDS on HAART. AIDS Patient Care STDS, Larchmont, v. 19, no. 2, p. 70-77, Feb. 2005.

GILEVA, O.S. et al. Espectro de las manifestaciones orales de $\mathrm{VIH} / \mathrm{SIDA}$ em la región de Perm (Rusia) e identificación de lesiones orales linguales ulceronecrotizantes inducidas. Med. Oral. Patol. Oral Cir. Bucal, Valencia, v. 9, no. 3, p. 212-215, mayo/jul. 2004.

GREENWOOD, I.; ZAKRZEWSKA, J.M.; ROBINSON, P.G. Changes in the prevalence of HIV-associated mucosa disease at a dedicated clinic over 7 years. Oral Dis., Copenhagen, v. 8, no. 2, p. 90-94, Mar. 2002

KALLINGS, L.O. The first postmodern pandemic: 25 years of HIVIAIDS (Review). J. Intern. Med., Oxford, v. 263, no. 3, p. 218-243, Mar. 2008.

KAMIRU, H.N.; NAIDOO, S. Oral HIV lesions and oral health behaviour of HIV-positive patients attending the Queen Elizabeth II Hospital, Maseru, Lesotho. SADJ, Houghton, v. 57, no. 11, p. 479-482, Dec. 2002.

KERDPON, D. et al. Oral manifestations of HIV infection in relation to clinical and CD4 immunological status in northern and southern Thai patients. Oral Dis., Copenhagen, v. 10, no. 3, p. 138-144, May 2004.

KHONGKUNTHIAN, $P$. et al. Oral manifestations in HIV- positive adults from Northern Thailand. J. Oral Pathol. Med., Oxford, v. 30, no. 4, p. 220-223, Apr. 2001

KHONGKUNTHIAN, $\mathrm{P}$. et al. Case Report. Oro-facial manifestations of Penicillium marneffei infection in a Thai patient with AIDS. Mycoses, Berlin, v. 45, no. 9, p. 411-414, Nov. 2002.

LAGER, I. et al. Oral Kaposi's sarcoma: a clinicopathologic study from study from South Africa. Oral Surg. Oral Med. Oral Pathol. Oral Radiol. Endod., St. Louis, v. 96, no. 6, p. 701-710, Dec. 2003. 
MATEE, M.I.; SCHEUTZ, F.; MOSHY, J. Occurrence of oral lesions in relation to clinical and immunological status among HIV- infected adult Tanzanians. Oral Dis., Copenhagen, v. 6, no. 2, p. 106-111, Mar. 2000.

MEDEIROS, C. F. et al. Relação entre as manifestações estomatológicas, contagem de células CD4 + e carga viral em pacientes HIV positivos. Pesq. Bras. Odontoped. Clín. Integr., João Pessoa, v. 7, no. 3, p. 271-276, set./dez. 2007.

MUÑOZ, S.I.N. et al. Revisão sistemática de literature e metanálise: noções básicas sobre seu desenho, interpretação e aplicação na área da saúde. In: SIMPÓSIO BRASILEIRO DE COMUNICAÇÃO EM ENFERMAGEM, 8., 2002. Anais... Disponível em: < www.proceedings.scielo.br/scielo.php >. Acesso em:

NARANI, N; EPSTEIN, J. B. Classifications of oral lesion in HIV infection. J. Clin. Periodontol., Copenhagen, v. 28, no. 2, p. 137145, Feb. 2001.

PATTON, L. L. Sensitivity, specificity, and positive predictive value of oral opportunistic infections in adults with HIV/ AIDS as markers of immune suppression and viral burden. Oral Surg. Oral Med. Oral Pathol. Oral Radiol. Endod., St. Louis, v. 90, no. 2, p. 182-188, Aug. 2000.

PATTON, L.L. et al. Changing prevalence of oral manifestations of Human Immunodeficiency virus in the era of protease inhibitor therapy. Oral Surg. Oral Med. Oral Pathol. Oral Radiol. Endod., St. Louis, v. 89, no. 3, p. 299-303, Mar. 2000.

PINHEIRO, A. et al. Dental and oral lesions in HIV-infected patients: a study in Brazil. Int. Dent. J., London, v. 54, no. 3, p. 131-137, June 2004.

RAMIREZ-AMADOR, V. et al. The Changing clinical spectrum of Human Immunodeficiency Virus (HIV) - related oral lesions in 1000 consecutive patients a 12-year study in a referral center in Mexico. Medicine, Baltimore, v. 82, no. 1, p. 39-50, Jan. 2003.

RAMIREZ-AMADOR, V. et al. Oral lesion as clinical markers of highly active antiretroviral therapy failure: a nested case control study in Mexico City. Clin. Infect. Dis., Chicago, v. 45, no. 7, p. 925-932, Aug. 2007.

REZENDE, J.M. Imunodepressão e imunossupressão. Rev. Patol. Trop., [S.I.], v. 40, n. 2, p. 199-201, 2011.

SANJAR, F.A.; QUEIROZ, B.E.; MIZIARA, I.D. Otolaryngologic manifestations in HIV disease- clinical aspects and treatment. Braz. J. Otorhinolaryngol., São Paulo, v. 77, no. 3, p. 391-400, June 2011.

SCHMIDT-WESTHAUSEN, A.M. et al. Decline in the rate of oral opportunistic infections following introduction of highly active antiretroviral therapy. J. Oral Pathol., Copenhagen, v. 29, no. 7, p. 336-341, Aug. 2000.

SOUZA, L.B. et al. Manifestações orais em pacientes com AIDS em uma população brasileira. Pesq. Odont. Bras., São Paulo, v. 14, n. 1 , p. 79-85, jan./mar. 2000.

TIRWOMWE, J. F. et al. Oral manifestations of HIVIAIDS in clients attending TASO clinics in Uganda. Clin. Oral Invest., Berlin, v. 11, no. 3, p. 289-292, Sept. 2007.

TZUNG, T. Y. et al. Cutaneous manifestations of Human Immunodeficiency Virus Infection in Taiwan. Kaohsiung J. Med. Sci., China, v. 20, no. 5, p. 216-224, May 2004.
ZAKRZEWSKA, J. M.; ATKIN, P. A. Oral mucosal lesions in a HIVIAIDS oral medicine clinic. A nine year, cross-sectional, prospective study. Oral Health Prev. Dent., New Malden, UK, v. 1, no. 1, p. 73-79, 2003. 